\title{
Characterization of feet temperature
}

Cite as: AIP Conference Proceedings 1558, 574 (2013); https://doi.org/10.1063/1.4825556

Published Online: 17 October 2013

Soraia Carvalho, and Ana I. Pereira

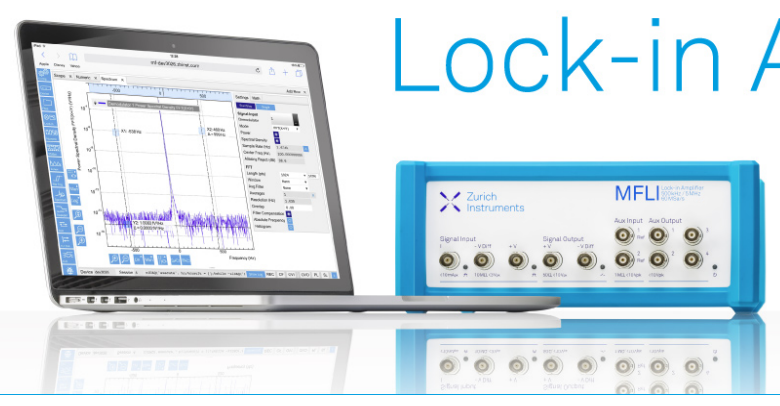

Amplifiers

Zurich

- Instruments

Watch the Video 


\title{
Characterization of Feet Temperature
}

\author{
Soraia Carvalho* and Ana I. Pereira*,† \\ *Polytechnic Institute of Bragança, Portugal \\ ${ }^{\dagger}$ ALGORITMI, University of Minho, Portugal
}

\begin{abstract}
In this work it was studied the problem of finding the best approximation to characterize the feet temperature distribution. For this study it was considered the nonlinear optimization, specifically the pattern search method for local optimization and the genetic algorithm method for global optimization. Using these nonlinear optimization methods we were capable to identify the function that fits the data obtained through thermographic images.
\end{abstract}

Keywords: Nonlinear Optimization. Temperature Distribution. Global optimization.

PACS: $02.60 . \mathrm{Pn}$

\section{INTRODUCTION}

Mathematical modeling has been used for the study, analysis and understanding of many problems and real phenomena in various areas such as engineering, economics, medicine, among the others.

In this study, it was used thermal plantar images to support a mathematical model for foot temperature distribution. It was used the nonlinear optimization technique to minimize the square error between the mathematical modeling and the real temperature distribution. The images were obtained by a thermal camera and then applied image processing techniques using the Matlab software and, finally, it was obtained the temperature matrix.

The main idea of this work is to characterize the behavior of the temperature distribution in the healthy foot and in the diabetic foot, and also, verify if there exists differences in the temperature distribution between two types of foot (with and without pathology).

The paper is organized as follows. Section 2 describes the materials and methods used in this study. Section 3 provides some numerical results and the last section presents some conclusions and ideas for future work.

\section{MATERIALS AND METHODS}

\section{Protocol}

In this study we have images of healthy and diabetic feet. The healthy feet images were recruited from Polytechnic Institute of Bragança. The diabetic feet images were obtained in old people's home Santa Casa da Misericórdia, at Bragança.

The images were collected by a thermal camera (FLIR 365) positioned at a fixed distance of one meter of the patient's feet.

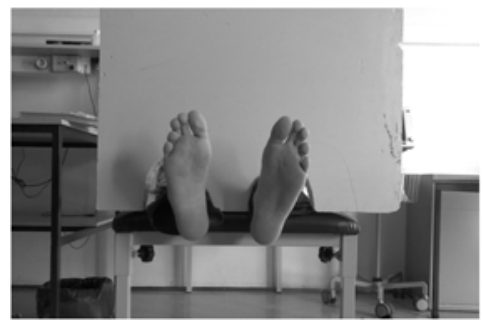

FIGURE 1. Isolation of the feet temperature. 
The subjects were guided to keep resting supine position without shoes or socks for ten minutes, before measurement, to stabilize the feet temperature. A rigid foam plate was placed over the ankles to isolate the temperature of feet from the body of the volunteer, as it can seen in the Fig. 1. The total time of data acquisition process did not exceed fifteen minutes. For more details, please see [1, 2, 3, 4].

Infrared thermography is a technique that aims to measure, in real time, the temperature variation of a specific body location. In our case, this location is the feet. The obtained image has a color variation taking into account the temperature of the skin of the feet. It is through image processing techniques that it is obtained an image with good color contrast [5].

The next figure will demonstrate the difference between the healthy foot and the diabetic foot, represented in thermal images. The diabetic foot and foot ulcers are serious threats to patients and must always be treated. So, this study has the intention to characterize the diabetic foot in order to have a early diagnostic [6].
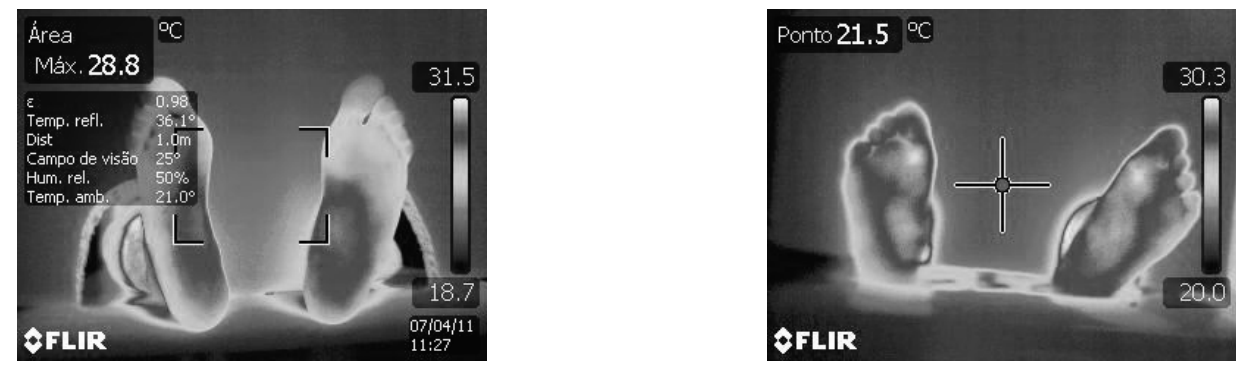

FIGURE 2. Healthy (on the left side) and Diabetic feet (on the right side).

As it can be seen in the Fig. 2, there are a range of colors to represent the feet temperature distribution. In our case, a hot spot color (the clearest spot), corresponds to a high temperature at that location. As the temperature decreases, the spot color will be closer to a cold color (the darkest spot). The objective of this study is to find the best approximation for the data obtained in the matrix of the feet temperature distribution.

\section{Method}

Consider the plantar image, $l$, obtained using a thermographic machine. Each thermographic image, $l$, was saved in the Matlab software computer, through a matrix temperature, $t_{i j}$, with size $M^{l} \times N^{l}$. For each image $l$, it was analyzed six different regions presented in the Fig. 3.

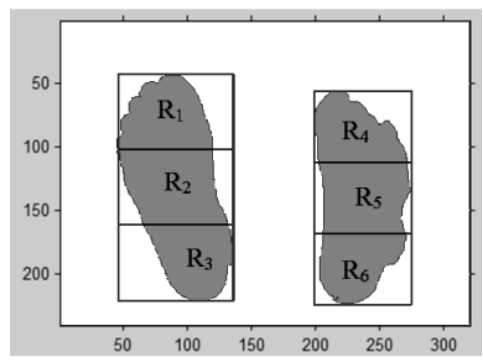

FIGURE 3. Feet regions.

For each region, $R_{k}^{l}$, for $k=1, \ldots, 6$, it was obtained the matrix data with temperature distribution with size $M_{k}^{l} \times N_{k}^{l}$.

In this study, it was considered five nonlinear functions to characterize the matrix data:

- $f_{1}(x, i, j)=x_{1} \sin ^{2}\left(x_{2} i\right)+x_{3} \cos ^{2}\left(x_{4} j\right)+x_{5}+x_{6} \sin \left(x_{7} i\right)+x_{8} \cos \left(x_{9} j\right)$

- $f_{2}(x, i, j)=x_{1} \sin ^{2}\left(x_{2} i+x_{3} j\right)+x_{4} \cos ^{2}\left(x_{5} i+x_{6} j\right)+x_{7}$;

- $f_{3}(x, i, j)=x_{1} \sin \left(x_{2} i+x_{3} j\right)+x_{4} \cos \left(x_{5} i+x_{6} j\right)+x_{7}$;

- $f_{4}(x, i, j)=x_{1} \sin \left(x_{2} i\right)+x_{3} \sin \left(x_{4} j\right)+x_{5} \cos \left(x_{6} i\right)+x_{7} \sin \left(x_{8} j\right)+x_{9}$; 
$\cdot f_{5}(x, i, j)=x_{1} \sin ^{2}\left(x_{2} i+x_{3} j+x_{4}\right)+x_{5} \cos ^{2}\left(x_{6} i+x_{7} j+x_{8}\right)+x_{9}+x_{10} \sin \left(x_{11} i+x_{12} j+x_{13}\right)+x_{14} \cos \left(x_{15} i+x_{16} j+\right.$ $\left.x_{17}\right)+x_{18}$.

The main objective of this work is to identify what function is the best approximation for each region $R_{k}^{l}$, for $k=1, \ldots, 6$. For that, we need to solve, for each function $f_{w}$, for $w=1, \ldots, 5$, the following nonlinear unconstrained problem

$$
\min \sum_{i=1}^{M_{k}^{l}} \sum_{j=1}^{N_{k}^{l}}\left(t_{i j}-f_{w}(x, i, j)\right)^{2}
$$

where $t_{i j}$ is the temperature matrix coefficient, $(i, j)$ represent the pixels positions, $M_{k}^{l}$ and $N_{k}^{l}$ is the matrix dimensions (rows and columns, respectively) associated to the region $R_{k}^{l}$, for $k=1, \ldots, 6$ and $l=1, \ldots, 6$.

To solve the nonlinear optimization problem it was used the local method pattern search (PS) and for the global methods, genetic algorithm (GA) and hybrid genetic algorithm (HGA).

The Pattern Search method (PS) is a direct method that finds a minimum of the unconstrained optimization problem, where the objective function is not necessarily differentiable [7, 8].

The genetic algorithm (GA) is based on a technique of random search that has the aim of finding the global solution. In this case, it was tested the simple version of the genetic algorithm and the genetic algorithm combined with a local search, known as hybrid genetic algorithm (HGA) [9].

\section{NUMERICAL RESULTS}

The numerical results were obtained using Intel(R) Core(TM) i7-3517U CPU 1.90GHz with 8.0 GB of RAM.

For this study, it was used three healthy feet images and three diabetic feet images. It was used a random vector as a initial point and each optimization problem was solved ten times.

The following table presents the numerical results, for the local method pattern search (PS) and for the global methods, genetic algorithm (GA) and hybrid genetic algorithm (HGA). It was used the predefined functions in the global optimization toolbox of the matlab software to solve the optimizations problems.

The table presents the average of the best solution obtained for each region and each function.

As we can see, the best mathematical model in studied was the function $f_{5}$, since the best solution is near of zero.

The method that obtain better results was the hybrid genetic algorithm method, however for the function $f_{1}$, the best approximations were always obtained by pattern search method.

For the mathematical models $f_{1}, f_{2}, f_{3}$ and $f_{4}$ there isn't a significant difference in the best solution when compare the data obtained from the healthy and diabetic foot. When analyzed the numerical results obtained with function $f_{5}$, it is possible to conclude that exists significant differences, in some regions, as for example $R_{1}, R_{5}$ and $R_{6}$.

\section{CONCLUSIONS AND FUTURE WORK}

In this work it was analyzed some thermal plantar images in order to define a mathematical model for the feet temperature distribution. It was used the nonlinear optimization technique to minimize the square error between the mathematical modeling and the real temperature distribution.

The main conclusion of this work is that the $f_{5}$ function approximates the numerical data in a better way. When compared the healthy feet with the diabetic ones, we can see that there are some differences for some feet regions.

As future work it should be tested other mathematical models and nonlinear optimization techniques. Testing other variants of the $f_{5}$ function can be another idea for getting better results. This study should be extended by using more thermographic images of healthy and diabetic feet. This study can be also expanded to patients with other types of diseases that affect directly their feet. 
TABLE 1. Average of the best solution.

\begin{tabular}{|c|c|c|c|c|c|c|c|}
\hline \multirow{3}{*}{ Region } & \multirow{3}{*}{ Function } & \multicolumn{3}{|c|}{ Healthy feet } & \multicolumn{3}{|c|}{ Diabetic feet } \\
\hline & & \multirow{2}{*}{$\begin{array}{c}\text { Local } \\
\text { PS } \\
\end{array}$} & \multicolumn{2}{|c|}{ Global } & \multirow{2}{*}{$\begin{array}{c}\text { Local } \\
\text { PS } \\
\end{array}$} & \multicolumn{2}{|c|}{ Global } \\
\hline & & & GA & HGA & & GA & HGA \\
\hline \multirow{5}{*}{$R_{1}$} & $f_{1}$ & $4.2 \mathrm{E} 2$ & 2.4E4 & $1.3 \mathrm{E} 3$ & $4.2 \mathrm{E} 2$ & $2.4 \mathrm{E} 4$ & $1.6 \mathrm{E} 3$ \\
\hline & $f_{2}$ & $1.3 \mathrm{E} 3$ & $3.2 \mathrm{E} 4$ & $2.5 \mathrm{E} 2$ & $7.6 \mathrm{E} 2$ & $3.2 \mathrm{E} 4$ & $2.5 \mathrm{E} 2$ \\
\hline & $f_{3}$ & $1.6 \mathrm{E} 3$ & $3.6 \mathrm{E} 4$ & $2.0 \mathrm{E} 2$ & $1.4 \mathrm{E} 3$ & $3.4 \mathrm{E} 4$ & $3.4 \mathrm{E} 2$ \\
\hline & $f_{4}$ & $7.0 \mathrm{E} 2$ & 2.7E4 & $6.6 \mathrm{E} 2$ & $7.3 \mathrm{E} 2$ & 2.6E4 & $8.1 \mathrm{E} 2$ \\
\hline & $f_{5}$ & $3.0 \mathrm{E} 1$ & $2.2 \mathrm{E} 4$ & $2.4 \mathrm{E} 1$ & $1.5 \mathrm{E} 1$ & $2.2 \mathrm{E} 4$ & $5.0 \mathrm{E} 0$ \\
\hline \multirow{5}{*}{$R_{2}$} & $f_{1}$ & $4.0 \mathrm{E} 2$ & $2.2 \mathrm{E} 4$ & $1.2 \mathrm{E} 3$ & $4.0 \mathrm{E} 2$ & 2.4E4 & $2.1 \mathrm{E} 3$ \\
\hline & $f_{2}$ & $4.8 \mathrm{E} 2$ & $3.2 \mathrm{E} 4$ & $2.0 \mathrm{E} 2$ & $8.5 \mathrm{E} 2$ & 3.1E4 & $2.0 \mathrm{E} 2$ \\
\hline & $f_{3}$ & $6.0 \mathrm{E} 2$ & $3.5 \mathrm{E} 4$ & $5.5 \mathrm{E} 2$ & $1.2 \mathrm{E} 3$ & 3.6E4 & $1.9 \mathrm{E} 2$ \\
\hline & $f_{4}$ & $6.7 \mathrm{E} 2$ & 2.4E4 & $5.3 \mathrm{E} 2$ & 7.1E2 & 2.4E4 & $8.7 \mathrm{E} 2$ \\
\hline & $f_{5}$ & $1.3 \mathrm{E} 1$ & $2.3 \mathrm{E} 4$ & $0.4 \mathrm{E} 0$ & $6.7 \mathrm{E} 1$ & $2.3 \mathrm{E} 4$ & $1.3 \mathrm{E} 1$ \\
\hline \multirow{5}{*}{$R_{3}$} & $f_{1}$ & $3.8 \mathrm{E} 2$ & $2.3 \mathrm{E} 4$ & $1.1 \mathrm{E} 3$ & $3.7 \mathrm{E} 2$ & $2.5 \mathrm{E} 4$ & $1.5 \mathrm{E} 3$ \\
\hline & $f_{2}$ & $5.6 \mathrm{E} 2$ & $3.2 \mathrm{E} 4$ & $2.0 \mathrm{E} 2$ & $9.3 \mathrm{E} 2$ & $3.2 \mathrm{E} 4$ & $2.0 \mathrm{E} 2$ \\
\hline & $f_{3}$ & $5.7 \mathrm{E} 2$ & $3.6 \mathrm{E} 4$ & $1.7 \mathrm{E} 2$ & $8.2 \mathrm{e} 2$ & 3.6E4 & $1.8 \mathrm{E} 2$ \\
\hline & $f_{4}$ & $6.4 \mathrm{E} 2$ & $2.6 \mathrm{E} 4$ & $9.2 \mathrm{E} 2$ & 8.3E2 & $2.6 \mathrm{E} 4$ & $9.1 \mathrm{E} 2$ \\
\hline & $f_{5}$ & $5.3 \mathrm{E} 1$ & $2.4 \mathrm{E} 4$ & $1.1 \mathrm{E} 0$ & 5.3E1 & $2.3 \mathrm{E} 4$ & $6.3 \mathrm{E} 0$ \\
\hline \multirow{5}{*}{$R_{4}$} & $f_{1}$ & $3.5 \mathrm{E} 2$ & 2.4E4 & $1.0 \mathrm{E} 3$ & $4.4 \mathrm{E} 2$ & $2.3 \mathrm{E} 4$ & $1.7 \mathrm{E} 3$ \\
\hline & $f_{2}$ & 7.1E2 & $3.1 \mathrm{E} 4$ & $1.8 \mathrm{E} 2$ & $1.2 \mathrm{E} 3$ & $3.3 \mathrm{E} 4$ & $1.8 \mathrm{E} 2$ \\
\hline & $f_{3}$ & $4.8 \mathrm{E} 2$ & $3.8 \mathrm{E} 4$ & $2.5 \mathrm{E} 2$ & 1.4E3 & 3.6E4 & 3.3E2 \\
\hline & $f_{4}$ & $8.0 \mathrm{E} 2$ & $2.5 \mathrm{E} 4$ & $4.9 \mathrm{E} 2$ & 6.3E2 & $2.6 \mathrm{E} 4$ & $5.3 \mathrm{E} 2$ \\
\hline & $f_{5}$ & $4.3 \mathrm{E} 1$ & $2.3 \mathrm{E} 4$ & $0.5 \mathrm{E} 0$ & 3.2E1 & $2.2 \mathrm{E} 4$ & $4.7 \mathrm{E} 0$ \\
\hline \multirow{5}{*}{$R_{5}$} & $f_{1}$ & $3.3 \mathrm{E} 2$ & 2.4E4 & $1.3 \mathrm{E} 3$ & $3.3 \mathrm{E} 2$ & $2.5 \mathrm{E} 4$ & $1.3 \mathrm{E} 3$ \\
\hline & $f_{2}$ & $1.0 \mathrm{E} 3$ & $3.1 \mathrm{E} 4$ & $1.8 \mathrm{E} 2$ & $1.1 \mathrm{E} 3$ & $3.2 \mathrm{E} 4$ & $1.7 \mathrm{E} 2$ \\
\hline & $f_{3}$ & $6.3 \mathrm{E} 2$ & $3.6 \mathrm{E} 4$ & 3.1E2 & 9.2E2 & 3.6E4 & $3.0 \mathrm{E} 2$ \\
\hline & $f_{4}$ & $5.7 \mathrm{E} 2$ & $2.5 \mathrm{E} 4$ & $4.7 \mathrm{E} 2$ & $5.7 \mathrm{E} 2$ & 2.6E4 & $4.5 \mathrm{E} 2$ \\
\hline & $f_{5}$ & 2.7E0 & $1.8 \mathrm{E} 4$ & 3.0E-4 & 1.1E2 & $2.2 \mathrm{E} 4$ & $1.4 \mathrm{E} 1$ \\
\hline \multirow{5}{*}{$R_{6}$} & $f_{1}$ & $3.0 \mathrm{E} 2$ & $2.3 \mathrm{E} 4$ & $6.5 \mathrm{E} 2$ & $3.0 \mathrm{E} 2$ & $2.5 \mathrm{E} 4$ & $1.0 \mathrm{E} 3$ \\
\hline & $f_{2}$ & 6.4E2 & 3.4E4 & $1.6 \mathrm{E} 2$ & $9.6 \mathrm{E} 2$ & $3.2 \mathrm{E} 4$ & $1.6 \mathrm{E} 2$ \\
\hline & $f_{3}$ & 9.3E2 & $3.9 \mathrm{E} 4$ & $1.5 \mathrm{E} 2$ & 4.7E2 & $3.8 \mathrm{E} 4$ & $1.5 \mathrm{E} 2$ \\
\hline & $f_{4}$ & $5.4 \mathrm{E} 2$ & $2.5 \mathrm{E} 4$ & $6.0 \mathrm{E} 2$ & $6.9 \mathrm{E} 3$ & $2.5 \mathrm{E} 4$ & $4.8 \mathrm{E} 2$ \\
\hline & $f_{5}$ & $9.5 \mathrm{E} 1$ & $2.3 \mathrm{E} 4$ & $5.7 E-6$ & 1.4E2 & $2.4 \mathrm{E} 4$ & 2.7E1 \\
\hline
\end{tabular}

\section{REFERENCES}

1. D. A. Bento, Modelação matemática da variação da temperatura no pé, Polytechnic Institute of Bragança - Portugal, 2011.

2. D. Bento, A. I. Pereira and F. Monteiro, Mathematical model of feet temperature. Numerical Analysis and Applied Mathematics, Volumes I-III (1389) Book Series: AIP Conference Proceedings, ISSN 978-0-7354-0956-9, pp. 787-790, 2011.

3. D. Bento, A. I. Pereira and F. Monteiro, Monitoring feet temperature using thermography, Computational vision and medical image processing, Taylor \& Francis Group, London, pp. 189-191, ISBN: 9780415683951, 2011.

4. S. Carvalho and A. I. Pereira, Modelação Matemática da Temperatura do Pé, XVI Congresso da Associação Portuguesa de Investigação Operacional, Bragança, pp. 56-57, 2013.

5. N. A. Diakides and J. D. Bronzino, Medical Infrared Imaging, Taylor \& Francis Group, New York, 2008.

6. T. Holt and S. Kumar, ABC of Diabetes, Sixth Edition, Chapter 14 pp. 64-71, BMJBooks, 7Summits, 2010

7. E. D. Dolan, R. M. Lewis and V. J. Torczon, On the local convergence of pattern search, SIAM Journal on Optimization, Vol 14 (2), pp. 567-583, 2003

8. T. G. Kolda, R. M. Lewis, and V. Torczon, Optimization by direct search: new perspectives on some classical and modern methods, SIAM Review, 45, 385 - 482, 2003.

9. S. Carvalho, Modelação Matemática da Variação da Temperatura do Pé, Final project of Biomedical Course, Polytechnic Institute of Bragança - Portugal, 2012. 